\title{
Childhood attention-deficit/hyperactivity disorder
}

\author{
Nienke Verkuijl specialty trainee ${ }^{1}$, Marian Perkins consultant ${ }^{2}$, Mina Fazel NIHR postdoctoral \\ research fellow ${ }^{1}$ consultant $^{3}$
}

${ }^{1}$ Department of Psychiatry, University of Oxford, Oxford OX3 7JX, UK; ${ }^{2}$ Child and Adolescent Neuropsychiatry Service, Oxford Health NHS Foundation Trust, Oxford, UK; ${ }^{3}$ Children's Psychological Medicine, The Children's Hospital, Oxford University Hospitals NHS Trust, Oxford, UK

Attention-deficit/hyperactivity disorder (ADHD) is the second most common psychiatric disorder of childhood. ${ }^{1}$ The 2010 Global Burden of Disease Study found that worldwide point prevalence rates of childhood ADHD were $2.2 \%$ in males and $0.7 \%$ in females. ${ }^{2}$ However, the diagnosis rates of and treatment approaches to ADHD vary worldwide, which feeds some of the uncertainties that have become a hallmark of the management of ADHD.

ADHD presents with persistent and impairing symptoms of inattention, hyperactivity, and impulsivity. Children with ADHD can be negatively labelled or treated differently at school and at home, as they struggle to concentrate, sit still, and think before acting, which can make learning and functioning in a typical classroom environment challenging. Furthermore, social interactions can be difficult, leading to rejection by peers ${ }^{3}$ and an often strained relationship with parents. ${ }^{4}$ In combination, these factors can create secondary adversities, such as greater risk of poor school attainment and exclusion, misuse of substances, and involvement with the criminal justice system (fig $1 \Downarrow)^{5-8}$

ADHD is a disorder that attracts considerable debate and controversy. Data indicate that in some areas overdiagnosis is a problem, ${ }^{9}$ with concerns about the misuse of psychostimulants raised within the healthcare profession and elsewhere. However, the negative impact of unrecognised and untreated symptoms of severe ADHD must not be underestimated for children and their families. Both behavioural interventions and drugs improve outcomes compared with no intervention, although the functioning of affected children in the long term remains below that of their age and demographically matched peers. ${ }^{7}$

This review aims to provide an evidence based overview of the assessment and management of ADHD for clinicians. We also discuss some of the driving factors that may be behind the conflicting picture produced in the academic literature and popular science about ADHD, although a comprehensive assessment of these issues is beyond the scope of this review.

\section{What causes it?}

ADHD is due to both heritable and non-heritable factors. ${ }^{10}$ Twin studies indicate a high heritability, of around 70-80\%. ${ }^{11}$ ADHD is associated with several genes, some of which are common to other psychiatric disorders ${ }^{12}$; the genes are linked to dopaminergic and serotonergic pathways. Further associations with ADHD include maternal alcohol and substance misuse during pregnancy, low birth weight, prematurity, nutritional deficiencies, exposure to environmental toxins, and early psychosocial adversity. ${ }^{10}$

\section{What are the current debates and controversies surrounding ADHD?}

The diagnosis and treatment of ADHD have caused debate in many arenas, including within health and education professions, ${ }^{13-15}$ the media, and the general public. ${ }^{16}$ Although the core symptoms of ADHD lie at one end of the normal distribution of behaviour, a major debate has taken place as to whether ADHD is actually a disorder, and, if it is a disorder, where the diagnostic cut-off lies. ${ }^{15}$ However, it is noted that a large body of family, twin, and adoption studies converge to show that ADHD is highly heritable. ${ }^{17}$ Twin studies have consistently shown that ADHD has a heritability of around $80 \%$ for monozygotic and 40\% for dizygotic twins. ${ }^{10} 18-20$

Some of the reasons for this conflicting picture include:

\section{Variation in prevalence and treatment rates}

The wide variation in reported global prevalence and treatment rates is of concern and has been described as precipitating a confidence crisis in psychiatric diagnosis. ${ }^{21}{ }^{22}$ This variation was highlighted by two studies from the United States and United Kingdom; both explored parent reported ADHD diagnosis "ever" made. The US study reported a $42 \%$ increase in ADHD diagnoses from 2003-11, with $8.8 \%$ having a current diagnosis of ADHD. ${ }^{23}$ The UK study reported a prevalence of $1.7 \%$, with 


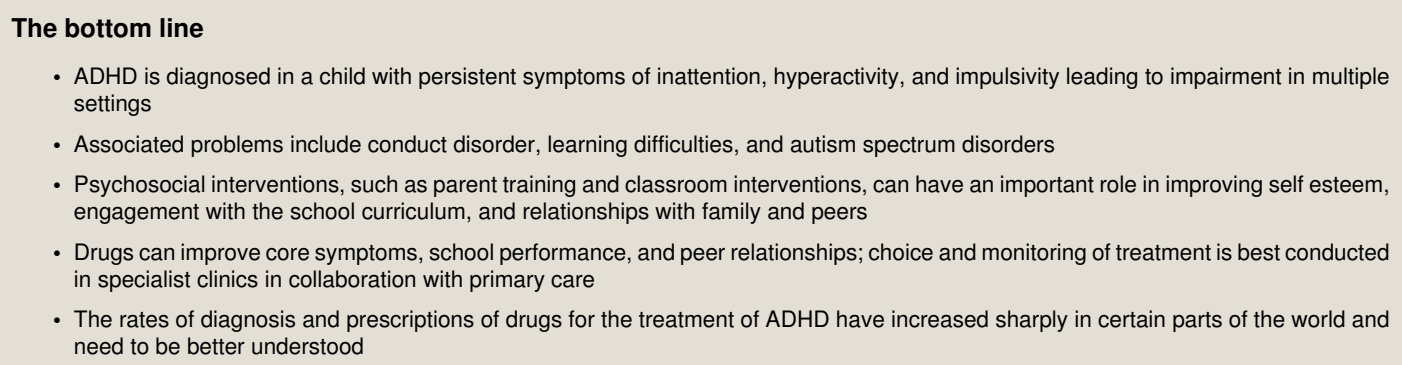

\section{Sources and selection criteria}

We searched PubMed for meta-analyses, systematic reviews, and randomised controlled trials on epidemiology and drug and non-drug treatments of ADHD published from January 2004 to December 2013 (and updated December 2014). We also read the national and international guidelines for ADHD by the National Institute for Health and Care Excellence, the European Guidelines for Hyperkinetic Disorders, the American Academy of Pediatrics, and the American Academy of Child and Adolescent Psychiatry. Further landmark studies were added, and we also sought additional expert opinion.

\section{How patients were involved in the creation of this article}

We sought accounts from children, adolescents, and young adults with ADHD and their parents on their experience of healthcare and include some of these accounts as part of this review to provide essential information on the perceptions of drugs and care. This review was changed as a result of child and parent feedback, with greater emphasis then placed on different treatments and more information given on different drugs, as these were common areas of uncertainty.

no evidence of an increase between 1999 and 2009. ${ }^{124}$ Overall, $6.1 \%$ of children in the US receive drugs for ADHD, in contrast with an estimated $0.8 \%$ in the UK. ${ }^{25}$

\section{Location}

Over and under diagnosis and treatment in certain geographical and population groups are additional factors. This is illustrated by the Great Smoky Mountain longitudinal study in the US. To identify those with ADHD, 4500 children were screened and those with behavioural problems were interviewed and observed as well as parent and teacher reports collected. Overall, 3.4\% of the children were found to have ADHD, although 7.3\% were taking psychostimulants. ${ }^{9}$ Interestingly, children living below the poverty line were less than half as likely to receive drugs.

\section{Cultural expectations of behaviour}

Current diagnostic frameworks for ADHD inevitably leave a subjective element, determining the degree to which functioning is affected. There is therefore a "zone of ambiguity" affecting diagnosis. ${ }^{13}{ }^{14}$ The judgment made by parents, teachers, and clinicians is influenced by cultural expectations of children's behaviour. ${ }^{14}$ Recent debate has also raised the problem that psychostimulants in some countries or socioeconomic groups are being misused as cognitive enhancers for young people, for which there is some evidence in normal controls. ${ }^{26-28}$ The clinician's role is to identify those children with a history of functional impairment as a result of attentional difficulties who might best benefit from drug treatment, balancing the benefits and potential side effects of drugs.

\section{Classification}

The two different diagnostic classification systems, the International Classification of Diseases (ICD) and the Diagnostic and Statistical Manual of Mental Disorders (DSM), may contribute to the variation in prevalence rates. This is because they each use different terms and diagnostic criteria for ADHD. When the criteria change, as in the recent move from DSM-IV to DSM-5, the changes can make comparisons between studies difficult. ${ }^{142429}$ The DSM is used mainly in North America and is also used internationally for research, whereas the ICD-10 is mostly used in clinical contexts outside the USA. DSM-5 utilises the term "ADHD" and has made several changes to the classification of the disorder when compared to its predecessor, whereas the ICD-10 does not use ADHD but the term "hyperkinetic disorder," which is equivalent to severe ADHD. International efforts are attempting to unify the main diagnostic categories across these two classification systems. ${ }^{30}$

\section{Involvement of industry}

Financial interests and constraints can contribute to the complex interplay of factors. The pharmaceutical industry is reported to have influenced the current diagnostic inflation. ${ }^{21}{ }^{22}$ In addition, many researchers and patient support groups, as well as $37 \%$ of websites about ADHD, have received ADHD related grants from the pharmaceutical industry. ${ }^{31}{ }^{32}$ In the USA, drugs for ADHD are heavily advertised, and pharmaceutical companies are allowed to advertise directly to potential consumers and teachers, which can also influence consumption rates. ${ }^{33}$ Limited access to behavioural and psychological treatments may sway doctors and patients towards using drugs earlier in the ADHD management pathway. Furthermore, some health insurance policies require a diagnosis to be present for any reimbursement of treatment. ${ }^{14}$

\section{Strength of the evidence base}

There is a paucity of good quality experimental data on drug treatments from which to draw firm conclusions. This problem is not specific to ADHD and affects many decisions about drugs across child psychiatry, reflecting the difficulty in both securing funding and studying child populations under ideal experimental conditions. ${ }^{34}$ Therefore areas that would benefit from a stronger evidence base include the natural progression of ADHD and numerous questions around drug treatments, including long term effects, those subgroups most likely to benefit from treatment, and longitudinal outcomes of those receiving drugs compared with other treatments. ${ }^{35}$ 


\section{How is it assessed and diagnosed? Making the diagnosis}

Countries differ on their guidelines when stipulating who is allowed to make an ADHD diagnosis, with many countries, such as the USA and the Netherlands, having primary care physicians making the diagnosis, and other countries, such as the UK, having a paediatrician or child psychiatrist confirm a suspected diagnosis of ADHD. ${ }^{36} 37$

The three core symptoms of ADHD are inattention,

hyperactivity, and impulsivity. In combination these symptoms most often manifest as children struggling with schoolwork and being disorganised. Such children are often described as "constantly on the go" and have poor awareness of danger. Social interactions can be problematic because of the high level of activity, reduced awareness of others' space, impulsivity, and inability to sustain play or a conversation for longer than a few minutes. Children are susceptible to bullying or are easily encouraged to do "silly" things that get them into trouble.

Parents, especially mothers, often feel blamed for their child's behaviour, which can lead either to a reluctance to approach a doctor for help or to an eagerness to seek a diagnosis. ${ }^{38-40}$ The children may overhear negative comments, such as being described as "the most difficult" or the "worst behaved," and this can potentially impact on self esteem (fig $2 \Downarrow$ ).

It is important at this stage to rule out common disorders that can lead to similar presentations, such as problems with sleep, hearing, and vision. Behavioural problems should be of a severity to cause significant stress and disruption at home and in the classroom. If other causes are ruled out and the problems persist with moderate impairment, referral to specialist services for a diagnosis is recommended. Younger children, more commonly boys, can present with difficulties at school and, in extremis, school exclusion, ${ }^{6}$ whereas girls have more attentional difficulties and ADHD can often remain undiagnosed until later when academic demands become greater. A referral to secondary care will be greatly aided by additional multidisciplinary reports-for example, from professionals working within the education sector, such as teachers, educational psychologists, and pastoral support staff. ${ }^{3641}$ Referral to a parenting course can be made for the parents of children aged less than 11 years awaiting specialist assessment. Professionals recommending a parenting course need to be mindful of implying that parents have poor parenting skills. They should instead stress that children with these difficulties often benefit from more intensive parenting.

Box 1 highlights the DSM-5 criteria for a diagnosis of ADHD. A thorough history and examination are essential to determine the correct diagnosis and assess commonly associated conditions and comorbidities (box 2).

In addition to questions on core symptoms using diagnostic criteria, the clinical interview should include:

- Presenting problems, history of difficulties, and current functioning. It should consider the children's experiences of their symptoms and include general questions around risk taking

- Pregnancy, birth history, and history of early neurodevelopment (milestones, language, attachment, sleep, feeding problems, early temperament, social-communication development)

- Medical history (tics, epilepsy, cardiac symptoms, gross and fine motor skills, vision, and hearing), drug history, and family medical history, especially cardiac, such as sudden death below 40 years or death associated with exercise

- Assessment of the level of global impairment at school, at home, and in a social context (a well validated tool for this is the Children's Global Assessment Scale $)^{54}$

Standardised questionnaires are widely used in the assessment and management of ADHD (see table on thebmj.com). Psychometric assessments can be useful if learning or communication difficulties are present. Chromosomal analysis and functional brain imaging are not routinely recommended.

\section{How is ADHD treated?}

The management of children with ADHD has to take place within a full understanding of the severity of their current difficulties, their socio-emotional needs, family circumstances, and educational environment. ${ }^{36}{ }^{47}$ In view of the lifelong trajectory of children with severe impairments, the role and timing of drugs at different ages will need to be considered. For example, children being managed with behavioural and family strategies may be additionally supported by the use of drugs at key periods of transition or other stressors. Importantly, the management of ADHD in some families can potentially be complicated by undiagnosed and untreated ADHD in the parents. ${ }^{25}$ Many supports available to families increasingly lie within education, social services, and the voluntary sector or the community, as well as in the healthcare setting.

Although the broad framework of assessment across the globe is relatively consistent for $\mathrm{ADHD}$, countries do vary in the degree to which psychosocial interventions are prioritised compared with drug interventions, for reasons described above. The ADHD guidelines in the UK, which are broadly similar to the European and US guidelines recommend parent training programmes and behavioural strategies. ${ }^{36}$ For severe ADHD, it is recommended that drugs should be offered alongside psychosocial interventions in children who are 6 years and older. ${ }^{367}$ The recommended investigations when starting drugs are:

- Physical examination-a cardiac examination to exclude any obvious abnormalities. Baseline pulse, blood pressure, height, and weight should be recorded

- Tests-electrocardiography only if there is a medical or family history of serious cardiac disease, a history of sudden death in young family members, or abnormal findings on cardiac examination. Blood tests are not routinely recommended

\section{Psychosocial interventions for ADHD}

The evidence base for many psychosocial interventions such as parent training, social skills training, cognitive training, or specific classroom interventions is limited..$^{55-59}$

Findings from a systematic review and meta-analysis in 2013 of randomised controlled trials of non-drug treatments for ADHD found no evidence for the efficacy of behavioural interventions involving children, parents, or teachers on core ADHD symptoms when using blinded assessors. There was evidence for a small but significant effect of behavioural interventions when studies used non-blinded assessors such as parents. $^{55}$

In considering the long term role of behavioural interventions compared with drugs, the Multimodal Treatment study of children with ADHD (MTA) is the largest randomised clinical trial, with eight years' follow-up. ${ }^{7}$ The behavioural treatment 


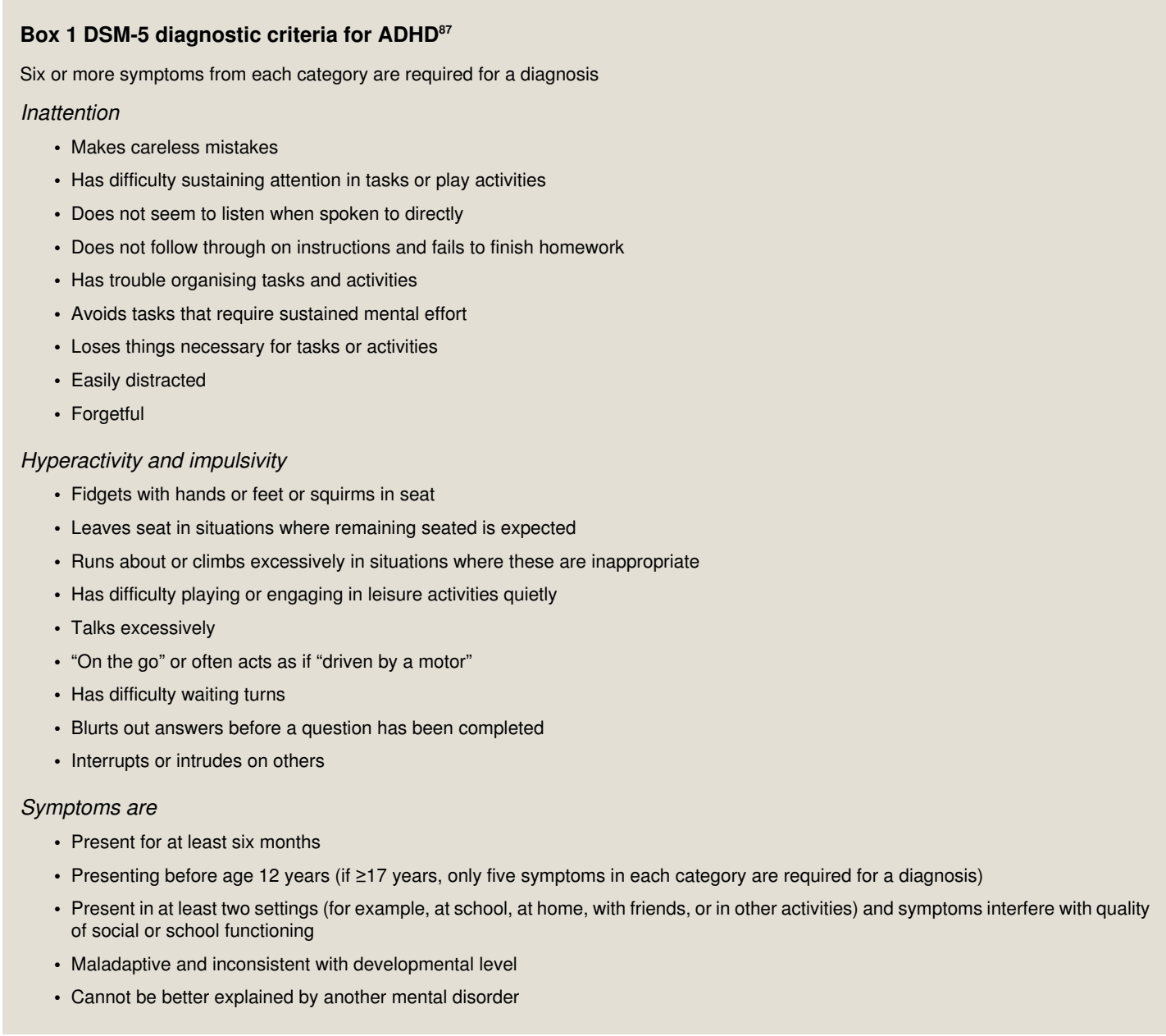

studied was extensive and included parent, child, and school based elements. The drug arm consisted of tightly titrated treatment regimens. After 14 months of treatment, core ADHD symptoms were better in the drug arm than both behavioural treatment and routine community care. The combined treatment of behavioural intervention and drugs did not yield significantly greater benefits, but provided some advantages for non-ADHD symptoms such as social interactions and internalising symptoms. After 14 months the study became a naturalistic observation. At 24 months (10 months after trial completion) those children who had received a combination of drugs and behavioural management needed significantly lower drug doses. ${ }^{60}$ At the eight year follow-up, however, the treatment groups did not differ on measures, including school attainment, criminal arrests, admissions to hospital for psychiatric disorders, or other relevant outcomes. ${ }^{7}$ The strongest positive predictor of long term outcome was behavioural and sociodemographic advantage and having a good response to any treatment.

Psychosocial interventions have, however, been shown to play an important role in the longer term management and treatment of comorbidities associated with ADHD, which can lead to improved overall functioning of children by improving their self esteem and peer and family relationships and making it easier for them to access the school curriculum. ${ }^{59}$

\section{Parent training for ADHD}

Many parents report benefits from parent training, although a meta-analysis and Cochrane review have highlighted how its evidence base remains poor. ${ }^{55}$ In the UK, however, NICE guidelines recommend it as a first line treatment for children aged 3 to 11 years. ${ }^{36}$ Parent training, as for example in the New
Forest Parenting programme ${ }^{61}$ (ADHD focused) and the Incredible Years programme (broad behavioural focus), includes psycho-education and techniques for managing challenging behaviours..$^{57}$ The training is usually group based and emphasises three $\operatorname{areas}^{63}$ :

Focus on making wanted behaviours explicit-This can be through praise and reward rather than through criticising unwanted behaviour, such as telling children to sit down instead of shouting at them to stop being naughty, and by ignoring screaming and tantrums. A more positive relationship can be promoted through activities such as play.

Making a clear set of rules for the family-The rules should be explicit, succinct, and consistently enforced by parents.

Disobedience and aggression need to be firmly and calmly dealt with-for example, by temporarily removing children from a situation.

Anticipating potentially difficult times of the day-In the context of busy family life, this entails proactively placing structure, distraction, or different activities at these times-for example, during key transitions, such as when returning home from school.

\section{Social skills training}

Social skills training includes learning appropriate verbal and non-verbal communication in social situations, understanding how to share and take turns, listening, and recognising other people's emotions. A recent Cochrane review on social skills training for children aged 5-18 years with ADHD found no evidence for or against this type of training. ${ }^{56}$ This may be because the deficit in children with ADHD is not in their social 


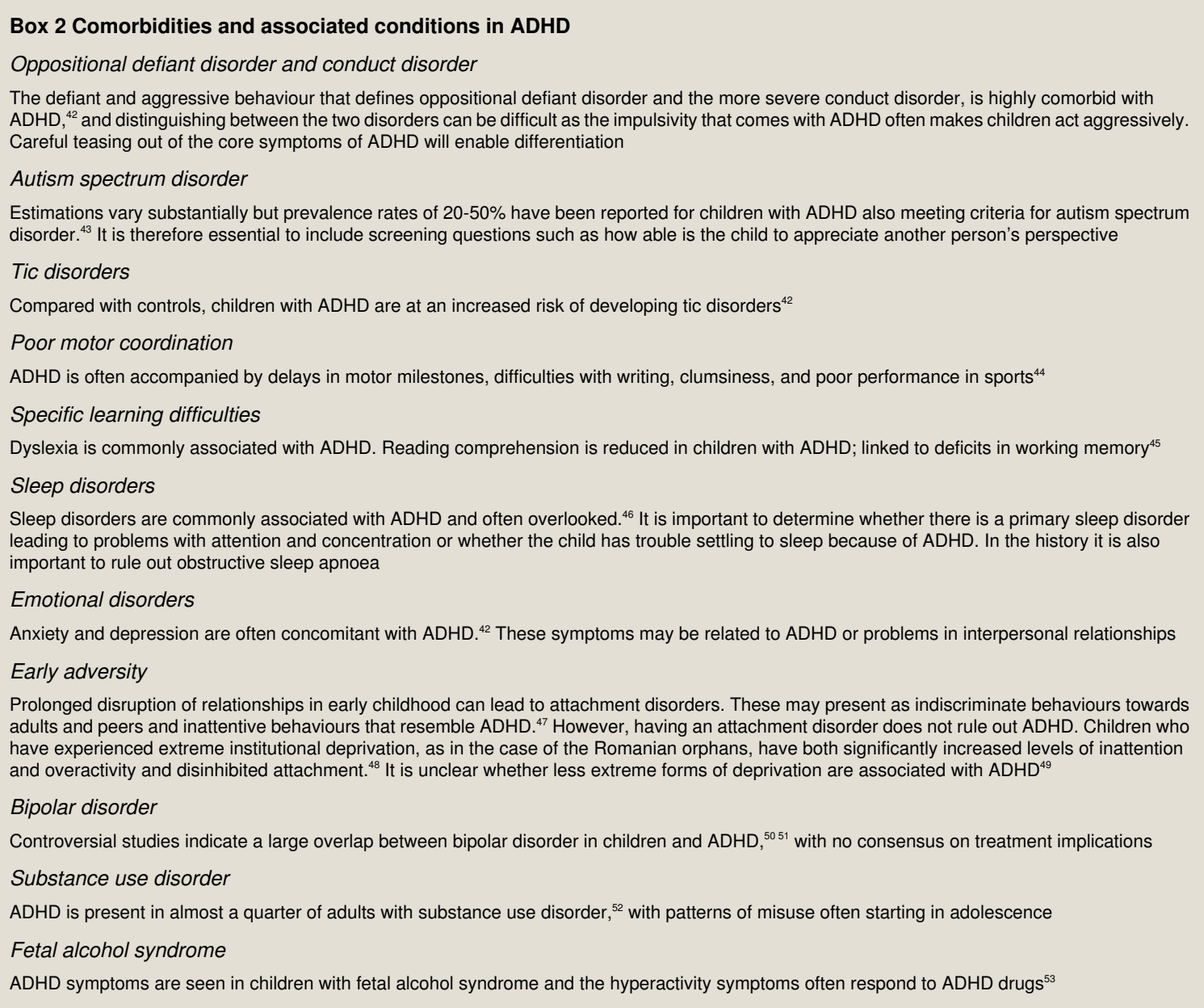

knowledge but in acting on a thought or idea before thinking about the consequences of this behaviour. ${ }^{64}$

\section{Cognitive training and cognitive behavioural therapy}

Cognitive training involves the training of attention and working memory, which are often considered part of "executive function." A systematic review and meta-analysis of randomised controlled trials of cognitive training for ADHD symptoms found no evidence of efficacy when using "probably" blinded assessors. ${ }^{55}$ Cognitive training was found to be effective when non-blinded assessors were used. For cognitive behavioural therapy (CBT), a review of the literature in 2010 found no studies indicating that CBT was helpful for ADHD symptoms in children. ${ }^{58}$ However, evidence from a subsequent non-randomised controlled trial indicates that CBT may be helpful for adolescents with ADHD who are receiving drugs and have residual difficulties. ${ }^{65}$ The effects were better for adolescents with comorbid anxiety and depression compared with those with comorbid conduct disorder or oppositional defiant disorder.

\section{Classroom interventions}

In traditional educational settings, children with ADHD can struggle to control their behaviour, achieve academically, and manage peer relationships. ${ }^{64}$ There is some evidence for the positive effects of school based intervention, although contextual factors and the perceptions of students and staff play an important role. ${ }^{66}$ Advice for teachers has been shown to be useful in managing children with ADHD, delivered, for example, in leaflets, with significant positive effects on attitudes and behaviour but not on attainment. ${ }^{67}$ Examples of effective classroom strategies include giving pupils a choice of two or more concurrently presented classroom activities ${ }^{67}$ sitting pupils near teachers so that they can be prompted if attention wanders, breaking down tasks and instructions ${ }^{64}$ and using immediate rewards (stickers or points) for wanted behaviour and mild penalties when "off task." ${ }^{98}$ Teachers find using daily report cards, which enhance teacher-parent collaboration, a useful intervention. ${ }^{66} \mathrm{~A}$ further study has shown how certain types of movement, for example sitting on an activity ball, can actually assist in focusing a child's attention, contrary to concerns that such activity might exacerbate inattention. ${ }^{69}$ There have been some positive academic effects with a class peer tutoring system. ${ }^{70}$ There is no evidence that classroom social skills training helps peer interactions for those with ADHD, ${ }^{56}$ but peer mediated resolution of conflicts has been associated with school-wide reductions in playground violence and negative interactions. ${ }^{71}$ Class-wide interventions-for example, to reduce distraction - are probably the least stigmatising to implement. ${ }^{66}$

\section{Dietary advice}

The importance of a healthy, balanced diet and regular exercise needs to be emphasised for all children, including those with ADHD. If there is a history suggesting the negative influence of certain foods then a food diary can help to determine these links. In the UK, NICE recommends that when certain foods are linked with difficult behaviour then specific elimination diets should be jointly managed by a dietician and the treating specialist. ${ }^{36} \mathrm{~A}$ randomised controlled trial using non-blinded assessors (parents) suggests that a "restricted elimination diet," whereby the diet was reduced to a few basic foods and then 
gradually broadened to assess other foods, found a dramatic reduction in ADHD symptoms in children not receiving drugs. ${ }^{72}$ However, a subsequent systematic review and meta-analysis of randomised controlled trials using blinded assessors found insufficient evidence for the efficacy of restricted elimination diets ${ }^{55}$ although the exclusion of artificial food colourants had a moderate positive effect on ADHD symptoms. The authors commented that children in both the restricted elimination diet and the artificial food colour exclusion trials were often preselected on the basis of sensitivity to certain food types, so the positive results may be applicable only to children with suspected food sensitivities. ${ }^{55}$ The use of free fatty acid supplementation can benefit some children with ADHD, as supported by the same meta-analysis of randomised controlled trials, with an effect size around 0.3 , which is significant but small compared with drugs, which can have effect sizes of $0.7-1.0 .{ }^{55}$ We have summarised the evidence for non-drug treatment for ADHD in table $1 \Downarrow$.

\section{Drugs}

Drugs can improve the three core symptoms of inattention, overactivity, and impulsivity, ${ }^{36}$ and there is evidence from randomised controlled trials to support the use of drugs for symptomatic and functional improvement in the short term. As described above, children without ADHD treated with drugs also show improvements in attention and focus, ${ }^{27}{ }^{28}$ leading to drugs being considered performance enhancing rather than as specific treatment for the psychopathology of ADHD. ${ }^{34}$

There are two main groups of clinically effective drugs for ADHD: psychostimulants, which increase available central dopamine and noradrenaline (for example, methylphenidate and dexamfetamine), and others, which include noradrenergic reuptake inhibitors (for example, atomoxetine). The choice of drug depends on the needs of the young person, formulation of the drug, ratio of immediate to extended release components, side effect profile, and cost (table $2 \Downarrow$ ).

A systematic review of randomised controlled trials provides evidence that psychostimulants and atomoxetine improve the core symptoms of ADHD and improve quality of life, although limitations of the studies for dexamphetamine and methylphenidate were noted. ${ }^{73}$ Short and long acting formulations of methylphenidate have been found to be equally effective. ${ }^{74}$ The overall effect size for methylphenidate is estimated at $1.0^{75}$ and for atomoxetine at $0.7,{ }^{76}$ with other studies reporting a number needed to treat of 3 for methylphenidate (extended release) and 5 for atomoxetine. ${ }^{74} \mathrm{~A}$ few studies have explored the experiences of children with ADHD receiving drugs - for example, one small study reported generally positive experiences of treatment. ${ }^{36}$ The children described putting up with the "annoying" aspects of drugs in return for improved relationships with peers as a result of less disruptive behaviour. The more common adverse effects of drugs for ADHD are nausea, headaches, sleep problems, slight increases in heart rate and blood pressure, and decreased appetite with associated weight loss and reduction in height; more details are provided in box $3 .^{77}$

Although there is evidence that current and active psychostimulant treatment (of any duration) is associated with symptomatic and functional improvement, longer term follow-up studies were not able to show beneficial effects of stimulant use on ADHD symptoms and overall functioning in the longer term. ${ }^{78}$ None of the studies accounted for the variable course of the disorder over childhood, drug adherence, and selection bias in treatment. ${ }^{35}$
In light of the evidence on the effectiveness of drugs for ADHD, the choice to start treatment should primarily be considered in severe cases where impairment is demonstrable in multiple areas of the child's life. An honest discussion with parents and older children about the benefits and uncertainties of treatment and possible adverse effects is recommended.

\section{Initiation, titration, and monitoring of drug treatment}

When drug treatment for ADHD is initiated and monitored in secondary care by child psychiatrists or paediatricians, primary care professionals have an important role in alerting overseeing specialists to problems in the overall treatment plan, such as non-compliance, or in expediting a review of the current treatment plan if difficulties arise. NICE recommends (based on effectiveness, side effect profile, and cost) methylphenidate as first line treatment for severe ADHD, followed by atomoxetine and then dexamphetamine. ${ }^{36}$

Initiation-Treatment regimens usually start with immediate release methylphenidate. ${ }^{36}$ Once-daily doses, although more costly, may be more practical and less stigmatising, and as psychostimulants are controlled drugs some schools do not want to administer them. Different preparations of immediate release and extended release are available (table 2) enabling flexibility if, for example, only the school day needs to be targeted or additional evening doses are required.

Titration-Response to treatment is initially monitored and titrated closely to determine the optimal dose, which should ideally be reached within a few weeks. ${ }^{36}$

Monitoring - Careful and systematic follow-up of children taking psychotropic drugs is of utmost importance. There should be clinical follow-up to monitor the psychological and behavioural effects of drugs after each change in dose, then at three months and routinely every six months, when height, weight, heart rate, and blood pressure should also be recorded (see box 3). These reviews should also include information from teachers to establish how well the symptoms are being controlled at school. Rating scales can be used to monitor clinical and behavioural change (see table on thebmj.com for examples of ADHD rating scales). ${ }^{79}$

\section{Duration of treatment and managing comorbidities}

After an adequate treatment response, drug treatment should be continued for as long as it remains effective, with at least biannual review. Drug holidays are not routinely recommended. The decision as and when to stop drugs is one that must be informed by what the children and parents want along with clinically perceived efficacy of treatment. If children no longer want to take drugs or the parents think they would like their child to try a period without drugs, then it is important to support this request. Drugs should ideally not be stopped at times of transition or increased stress (for example, when moving schools or sitting examinations), and summer holidays can be an opportune time for dose reduction. Table $3 \Downarrow$ provides more information on how to manage different drugs.

Often specialist advice is needed in the drug treatment of psychiatric comorbidities. Selective serotonin reuptake inhibitors for depression and some anxiety disorders are tolerated with methylphenidate. For sleep disorders, sleep hygiene should be considered a first line treatment, and specialist drug intervention, such as melatonin, may be useful, but only under specialist care. 


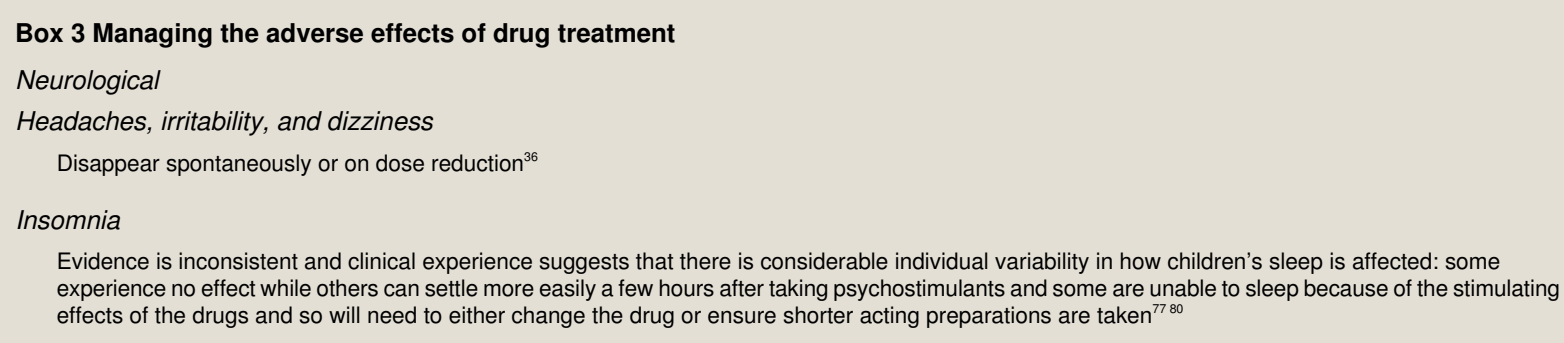

Not a contraindication to drug treatment, tics can sometimes be worsened by psychostimulant drugs and can be improved by atomoxetine. ${ }^{77}$ Observe over three months, as the natural, fluctuating course of tics can lead them to be more and less prominent over time, independent of drugs

\section{Epilepsy}

ADHD drugs lower the seizure threshold but can be used in children with established epilepsy with specialist monitoring ${ }^{77}$

\section{Cardiovascular}

Blood pressure

All ADHD drugs have the potential to increase blood pressure and pulse and so both must be routinely monitored. In most cases the changes are smal (average increases of 1-4 mm Hg for systolic and $1-2 \mathrm{~mm} \mathrm{Hg}$ for diastolic pressure and 1-2 beats/min for pulse), however in a subset of children (5-15\%) the increases in blood pressure and pulse may be above the 95th centile (measured three times within one visit with an age adjusted cuff) and children should be referred to specialist care ${ }^{81}$

\section{Severe cardiovascular events}

Children with a congenital heart defect, a history of cardiac symptoms (for example, syncope on exercise), or a positive family history of sudden death below the age of 40 years, are at risk of sudden death ${ }^{77}$ For these children extra caution needs to be taken with ADHD drugs and the involvement of a paediatric cardiologist is needed

\section{Gastrointestinal}

Nausea

Can disappear spontaneously or on dose reduction

\section{Weight loss and reduced appetite}

Psychostimulants reduce appetite with weight loss usually most pronounced in the first six months of treatment. ${ }^{82}$ Drugs are therefore best taken with or after food (advise additional snacks early in the morning or late in the evening)

\section{Liver damage}

May be a rare, idiosyncratic, and mostly reversible effect of atomoxetine.$^{83}$ Routine blood screening and monitoring are not recommended but advise seeking urgent medical opinion if abdominal pain, nausea, dark urine, or jaundice emerge ${ }^{36}$

\section{Growth \\ Reduced height}

Variable effect of psychostimulants on growth, with a delay of approximately $1 \mathrm{~cm} / \mathrm{year}$ in the first three years. The effect may be dose dependent and reversible when treatment is stopped. It is unclear whether stimulants have an effect on final adult height. Atomoxetine has similar effects on growth to stimulants ${ }^{84}$ If height measurements drop on the centile charts then a dose reduction is recommended, as can be switching to an alternative formulation or including some drug holidays in the treatment regimen. If height is significantly affected then referral to an endocrinologist is warranted ${ }^{77}$

\section{Psychological symptoms}

Psychotic symptoms

Very rarely delusions, hallucinations, and mania can emerge during treatment ${ }^{77}$

\section{Suicidal thoughts}

There is a reported slight increase in suicidal thoughts when starting atomoxetine; therefore mood must be monitored on initiation of treatment. Suicidal thoughts are not a contraindication to treatment, but dose reduction might be warranted

Other

\section{Drug misuse}

There is no evidence that treatment with psychostimulants increases the risk for later drug misuse ${ }^{85} \mathrm{~A}$ subsample of children with $\mathrm{ADHD}$ may be prone to misuse of psychostimulants. Dexamphetamine has the highest potential for misuse, and, in high risk cases, modified release methylphenidate, lisdexamfetamine, or atomoxetine should be considered ${ }^{77}$

\section{Sexual dysfunction}

Erectile and ejaculatory dysfunction and dysmenorrhoea are potential side effects of atomoxetine

We thank David Coghill, Tamsin Ford, Brian Green, Sandra Hallett, llja Holland-Kaye, Alison Maycock, Neysan Pucks, and Ruth Reed for helpful comments on earlier drafts of the review; the reviewers for their thoughtful and comprehensive comments; the BMJ editors who provided considerable input to the review, and all who in combination contributed to a much improved publication. We are grateful for permission from Professor Asherson and UKAAN for allowing us to revise a slide on ADHD impact. We thank the young adult and parent who kindly shared their experience with us.
Contributors: NV analysed the data. MF and NV wrote the first draft of the review. NV, MF, and MP revised drafts of the paper. MF is the guarantor.

Competing interests: We have read and understood the BMJ policy on declaration of interests and declare the following: none.

Provenance and peer review: Not commissioned; externally peer reviewed. 


\section{A young person's story}

I wasn't diagnosed until I was 11 when my family moved and I had to repeat a school year. I had performed well in a well-structured parochia school but started to slide when put in a more loosely structured school. I was prescribed medication for ADHD and given counselling on how to best organise and manage my time.

I never liked to be medicated (methylphenidate); the drugs gave me a dull and disconnected sense where I felt a physical distance between others and myself. My resistance to taking medication caused an ongoing fight between my mother and me. She wanted the best for me and bought me a fancy watch with five separate alarms to help me remember to take my meds.

In secondary school I learned to manage my ADHD: I used natural stimulants like coffee, began to meditate, and participated in attention intensive sports like rowing. These practices, along with the strategies I had learned to organise my time, helped me cope. At university I abandoned medication altogether when I was tempted to use it as a diet aid. Now, 17 years since diagnosis, I don't take medicine at all, though I think it would have been helpful at times during graduate school. I've found that things that fall inside my organisational structures get done quite well, and I'm surprised when employers laud my organisational skills, which are strong enough to organise whole teams and offices.

My family has not adapted to my increased capacities, and I find that interesting and sometimes very challenging. That said, if it's not on the list, it's likely not going to get done any time soon. And if I'm in between the notebooks I keep my list in, little's going to be accomplished.

\section{A parent's story}

In our son's last few years of school we realised that normal school challenges had become major challenges for him. Although he had managed an extremely busy school schedule, as school pressures increased we noticed that he had to work into the night to keep up with his studies. His normal fidgetiness and procrastination had become completely unmanageable. He would start new tasks before finishing others. His thoughts were scattered. He could not maintain focus for more than 10 minutes without getting up to snack or take a break. After six hours on an assignment he would have completed only 2-3 sentences.

For the first time our son lost his self esteem. He started to remark that he wasn't as smart as his classmates. I remember him telling me that sometimes he had to just stare at a blank white wall for 15 minutes to clear his mind.

Following medical review he was prescribed Concerta. Overnight his thoughts became more focused, he started to work methodically through his assignments, and normal sleep patterns came back. Most importantly, our son regained his sense of self esteem.

At university our son never lost the feeling that he should try and conquer ADHD without the benefit of medication. He began to realise that his ADHD symptoms were much more pronounced when he was forced to fulfill an academic requirement not in his core competencies. A physician counselled him to use Concerta selectively, to get through the more arduous tasks. She also helped him re-frame his perception of the condition not as a disability but as a special trait, which bestowed significant benefits on the aesthetic career path he had chosen.

\section{Questions for future research}

- What is the optimal duration for drug treatments and what are their long term effects?

- What are the best classroom strategies for managing ADHD, and how can they be implemented to support children and staff?

- Is parent training best delivered individually or in groups and is it more effective for certain clusters of symptoms?

- Can treatments be tailored for specific subgroups with ADHD?

- Does screening for ADHD and associated comorbidities play a role for school children at risk of exclusion or poor academic attainment?

- Is there a role for games, apps, and digital media in the management of ADHD?

- What are the long term outcomes of ADHD when children become adults, and which are the best treatment options for adults?

1 Ford T, Goodman R, Meltzer H. The British Child and Adolescent Mental Health Survey 1999: the prevalence of DSM-IV disorders. J Am Acad Child Adolesc Psychiatry 2003;42:1203-11

2 Erskine HE, Ferrari AJ, Nelson P, et al. Epidemiological modelling of attention-deficit/hyperactivity disorder and conduct disorder for the Global Burden of Disease Study 2010. J Child Psychol Psychiatry 2013;54:1263-74.

3 Gardner DM, Gerdes AC. A review of peer relationships and friendships in youth with ADHD. J Atten Disord 2013; published online 23 Sep.

4 Pimentel MJ, Vieira-Santos S, Santos V, et al. Mothers of children with attention deficit/hyperactivity disorder: relationship among parenting stress, parental practices and child behaviour. Atten Defic Hyperact Disord 2011;3:61-8.

5 Babinski LM, Hartsough CS, Lambert NM. Childhood conduct problems,

hyperactivity-impulsivity, and inattention as predictors of adult criminal activity. J Child Psychol Psychiatry 1999;40:347-55

6 Parker C, Whear R, Ukoumunne OC, et al. School exclusion in children with psychiatric disorder or impairing psychopathology: a systematic review. Emot Behav Difficult 2014; published online 20 Aug. doi:10.1080/13632752.2014.945741.

7 Molina BS, Hinshaw SP, Swanson JM, et al. The MTA at 8 years: prospective follow-up of children treated for combined-type ADHD in a multisite study. J Am Acad Child Adolesc Psychiatry 2009;48:484-500.

8 Sayal E, Washbrook E, Propper C. Childhood behavior problems and academic outcomes in adolescence: longitudinal population-based study. J Am Acad Child Adolesc Psychiatry 2015;54:360-8.

9 Angold A, Erkanli A, Egger HL, et al. Stimulant treatment for children: a community perspective. J Am Acad Child Adolesc Psychiatry 2000;39:975-84.

10 Thapar A, Cooper M, Eyre O, et al. Practitioner review: what have we learnt about the causes of ADHD? J Child Psychol Psychiatry 2013;54:3-16.

11 Faraone SV, Perlis RH, Doyle AE, et al. Molecular genetics of attention-deficit/ hyperactivity disorder. Biol Psychiatry 2005;57:1313-23.

12 Cross-Disorder Group of the Psychiatric Genomics Consortium. Identification of risk loci with shared effects on five major psychiatric disorders: a genome-wide analysis. Lancet 2013;381:1371-9.

13 Shah PJ, Morton MJ. Adults with attention-deficit hyperactivity disorder-diagnosis or normality? Br J Psychiatry 2013;203:317-9.

14 Parens E, Johnston J. Facts, values, and attention-deficit hyperactivity disorder (ADHD): an update on the controversies. Child Adolesc Psychiatry Ment Health 2009;3:1.

15 Batstra L, Nieweg EH, Hadders-Algra M. Exploring five common assumptions on attention deficit hyperactivity disorder. Acta Paedatr 2014;103:696-700.
16 Schwarz A, Cohen S. A.D.H.D. seen in $11 \%$ of U.S. children as diagnoses rise. New York Times 2013 Mar 31

17 Asherson P, Trzaskowski M. Attention-deficit/hyperactivity disorder is the extreme and impairing tail of a continuum. J Am Acad Child Adolesc Psychiatry 2015;54:249-50.

18 Levy F, Hay DA, McStephen M, et al. Attention-deficit hyperactivity disorder: a category or a continuum? Genetic analysis of a large-scale twin study. J Am Acad Child Adolesc Psychiatry 1997;36:737-44.

19 Stergiakouli E, Martin J, Hamshere ML, et al. Shared genetic influences between Attention-Deficit/ Hyperactivity Disorder (ADHD) traits in children and clinical ADHD. $J$ Am Acad Child Adolesc Psychiatry 2015;54:322-7.

20 Larsson $\mathrm{H}$, Anckarsater $\mathrm{H}$, Råstam M, et al. Childhood attention-deficit hyperactivity disorder as an extreme of a continuous trait: a quantitative genetic study of 8,500 twin pairs. J Child Psychol Psychiatry 2012;53:73-80.

21 Frances A. The past, present and future of psychiatric diagnosis. World Psychiatry 2013;12:111-2.

22 Monynihan R. A new deal on disease definition. BMJ 2011;342:1136.

23 Visser SN, Danielson ML, Bitsko RH, et al. Trends in the parent-report of health care provider-diagnosed and medicated attention-deficit/hyperactivity disorder: United States, 2003-2011. J Am Acad Child Adolesc Psychiatry 2014;53:34-46.

24 Russell G, Rodgers LR, Ukoumunne OC, et al. Prevalence of parent-reported ASD and ADHD in the UK: findings from the Millennium Cohort Study. J Autism Dev Disord 2014;44:31-40.

25 McCarthy S, Wilton L, Murray ML, et al. The epidemiology of pharmacologically treated attention deficit hyperactivity disorder (ADHD) in children, adolescents and adults in UK primary care. BMC Pediatr 2012;12:78.

26 Singh I, Filipe AM, Bard I, et al. Globalization and cognitive enhancement: emerging social and ethical challenges for ADHD clinicians. Curr Psychiatry Rep 2013;15:385.

27 Rapoport JL, Buchsbaum MS, Weingartner $\mathrm{H}$, et al. Dextroamphetamine. Its cognitive and behavioral effects in normal and hyperactive boys and normal men. Arch Gen Psychiatry 1980;37:933-43.

28 Del Campo N, Fryer TD, Hong YTA, et al. Positron emission tomography study of nigro-striatal dopaminergic mechanisms underlying attention: implications for ADHD and its treatment. Brain 2013;136:3252-70.

29 Swanson JM, Sergeant JA, Taylor E, et al. Attention-deficit hyperactivity disorder and hyperkinetic disorder. Lancet 1998;351:429-33.

30 First MB. Harmonisation of ICD-11 and DSM-V: opportunities and challenges. $\mathrm{Br} J$ Psychiatry 2009;195:382-90. 


\section{Additional educational resources}

Resources for healthcare professionals

National Institute for Health and Care Excellence guideline. Attention deficit hyperactivity disorder: diagnosis and management of ADHD in children, young people and adults (www.nice.org.uk/CG72)—evidence based guidelines on ADHD management in the UK

Cortese S, Holtmann M, Banaschewski T, et al. Current best practice in management of adverse events during treatment with ADHD medication in children and adolescents. J Child Psychol Psychiatry 2013;54:227-46. http://onlinelibrary.wiley.com/doi/10.1111/icpp. 12036/epdf-guidelines on management of adverse effects of medication produced on behalf of the European ADHD Guidelines Group The NIMH-funded Multimodal Treatment of Attention Deficit Hyperactivity Disorder (MTA) study (www.nimh.nih.gov/funding/clinicaltrials-for-researchers/practical/mta/multimodal-treatment-of-attention-deficit-hyperactivity-disorder-mta-study.shtml) -a multisite study designed to evaluate the main interventions for ADHD, including behavior therapy, drugs, and the combination of the two. First study published in 1999 and follow-up continues

\section{Resources for young people and their families}

The National Attention Deficit Disorder Information and Support Service UK. ADDISS (www.addiss.co.uk)-a patient and parent support organization

Young minds (www.youngminds.org.uk/for_children_young_people/whats_worrying_you/adhd)—information on ADHD tailored for young people

American Academy of Child and Adolescent Psychiatry and American Psychiatric Association (www.parentsmedguide.org/pmg_adhd. $\mathrm{html}$ - - ADHD drug information for parents

NHS choices. Attention Deficit Hyperactivity Disorder (ADHD) (www.nhs.uk/conditions/Attention-deficit-hyperactivity-disorder/Pages/ Introduction.aspx) -includes a video clip of an interview between a psychiatrist and a child with ADHD and his parents

Green C, Chee K. Understanding ADHD. A parent's guide to attention deficit hyperactivity disorder in children. Vermilion, 1997-a book with useful information and helpful strategies for parents and teachers

Hoopman K. All dogs have ADHD. Jessica Kingsley, 2008-a useful, light hearted book illustrating some aspects of ADHD www.healthline.com/health-slideshow/top-adhd-android-iphone-apps-a review of some of the ADHD apps available in 2015. Healthline (www.healthline.com/health/adhd) - has information and links to a range of blogs on ADHD and selected videos on YouTube and Tedx for young people and their families

ADHDVoices. YouTube. What's it like to have ADHD? (www.youtube.com/watch?v=HI7Ro1PUJmE)—short animated video of what it is like to have ADHD from a young person's perspective

31 Moncrieff J, Timimi S. The social and cultural construction of psychiatric knowledge: an analysis of NICE guidelines on depression and ADHD. Anthropol Med 2013;20:59-71.

32 Mitchell J, Read J. Attention-deficit hyperactivity disorder, drug companies and the internet. Clin Child Psychol Psychiatry 2012;17:121-39.

33 INCB. Report of the International Narcotics Control Board 2013. New York: United Nations, 2014.

34 Singh I. Beyond polemics: science and ethics of ADHD. Nat Rev Neurosci 2008:9:957-64

35 Hazell P. The challenges to demonstrating long-term effects of psychostimulant treatment for attention-deficit/hyperactivity disorder. Curr Opin Psychiatry 2011;24:286-90.

36 National Institute for Health and Care Excellence. Attention deficit hyperactivity disorder: diagnosis and management of ADHD in children, young people and adults. (Clinical guideline C72.) 2008, modified 2013. www.nice.org.uk/guidance/CG72.

37 American Academy of Pediatrics. ADHD: clinical practice guideline for the diagnosis, evaluation, and treatment of attention-deficit/hyperactivity disorder in children and adolescents. Pediatrics 2011;128:1007-22.

38 Klasen H, Goodman R. Parents and GPs at cross-purposes over hyperactivity: a qualitative study of possible barriers to treatment. Br J Gen Pract 2000;50:199-202.

39 Singh I. Doing their jobs: mothering with Ritalin in a culture of mother-blame. Soc Sci Med 2004:59:1193-205.

40 Sayal K, Taylor E, Beecham J, et al. Pathways to care in children at risk of attention-deficit hyperactivity disorder. Br J Psychiatry 2002;181:43-8.

41 Sayal K, Goodman R, Ford T. Barriers to the identification of children with attention deficit/hyperactivity disorder. J Child Psychol Psychiatry 2006;47:744-50.

42 Yoshimasu K, Barbaresi WJ, Colligan RC, et al Childhood ADHD is strongly associated with a broad range of psychiatric disorders during adolescence: a population-based birth cohort study. J Child Psychol Psychiatry 2012;53:1036-43.

43 Rommelse NN, Franke B, Geurts HM, et al. Shared heritability of attention-deficit/hyperactivity disorder and autism spectrum disorder. Eur Child Adolesc Psychiatry 2010;19:281-95.

44 Fliers $\mathrm{E}$, Vermeulen S, Rijsdijk F, et al. ADHD and poor motor performance from a family genetic perspective. J Am Acad Child Adolesc Psychiatry 2009;48:25-34

45 Miller AC, Keenan JM, Betjemann RS, et al. Reading comprehension in children with ADHD: cognitive underpinnings of the centrality deficit. J Abnorm Child Psychol 2013;41:473-83

46 Sung V, Hiscock H, Sciberras E, et al. Sleep problems in children with attention-deficit/hyperactivity disorder: prevalence and the effect on the child and family. Arch Pediatr Adolesc Med 2008:162:336-42.

47 Taylor E, Dopfner M, Sergeant J, et al. European clinical guidelines for hyperkinetic disorder-first upgrade. Eur Child Adolesc Psychiatry 2004;13(Suppl 1):17-30.

48 Rutter M, Beckett C, Castle J, et al. Effects of profound early institutional deprivation: an overview of findings from a UK longitudinal study of Romanian adoptees. Eur J Dev Psychol 2007:4:332-50.

49 Kreppner JM, Rutter M, Beckett C, et al. Normality and impairment following profound early institutional deprivation: a longitudinal follow-up into early adolescence. Dev Psycho 2007:43:931-46.

50 Biederman J, Faraone S, Mick E, et al. Attention-deficit hyperactivity disorder and juvenile mania: an overlooked comorbidity? J Am Acad Child Adolesc Psychiatry 1996;35:997-1008.

51 Hassan A, Agha SS, Langley K, et al. Prevalence of bipolar disorder in children and adolescents with attention-deficit hyperactivity disorder. Br J Psychiatry 2011;198:195-8.

52 Van Emmerik-van Oortmerssen K, van de Glind G, van den Brink W, et al. Prevalence of attention-deficit hyperactivity disorder in substance use disorder patients: a meta-analysis and meta-regression analysis. Drug Alcohol Depend 2012;122:11-9.

53 Peadon E, Rhys-Jones B, Bower C, et al. Systematic review of interventions for children with fetal alcohol spectrum disorders. BMC Pediatr 2009:9.35.
54 Shaffer D, Gould MS, Brasic J, et al. A Children's Global Assessment Scale (CGAS). Arch Gen Psychiatry 1983;40:1228-31.

55 Sonuga-Barke EJ, Brandeis D, Cortese S, et al. Nonpharmacological interventions for ADHD: systematic review and meta-analyses of randomized controlled trials of dietary and psychological treatments. Am J Psychiatry 2013;170:275-89.

56 Storebo OJ, Skoog M, Damm D, et al. Social skills training for Attention Deficit Hyperactivity Disorder (ADHD) in children aged 5 to 18 years. Cochrane Database Syst Rev 2011;12:CD008223.

57 Zwi M, Jones H, Thorgaard C, et al. Parent training interventions for Attention Deficit Hyperactivity Disorder (ADHD) in children aged 5 to 18 years. Cochrane Database Syst Rev 2011;12:CD003018.

58 Young S, Amarasinghe M. Practitioner review: non-pharmacological treatments for ADHD: a lifespan approach. J Child Psychol Psychiatry 2010;51:116-33.

59 MTA Cooperative Group. A 14-month randomized clinical trial of treatment strategies for attention-deficit/hyperactivity disorder. Arch Gen Psychiatry 1999;56:1073-86.

60 MTA Cooperative Group. National Institute of Mental Health Multimodal Treatment Study of ADHD follow-up: 24-month outcomes of treatment strategies for attention-deficithyperactivity disorder Pediatrics 2004;113:754-61.

61 Sonuga-Barke EJ, Daley D, Laver-Bradbury C, et al. Parent-based therapies for preschoo Attention-Deficit/Hyperactivity Disorder: a randomized, controlled trial with a community sample. J Am Acad Child Adolesc Psychiatry 2001;40:402-8.

62 Webster-Stratton C, Hancock L. Parent training for young children with conduct problems: content, methods and therapeutic process. In: Briesmeister JM, Schaefer CE, eds. Handbook of parent training: parents as co-therapists for children's behaviour problems. 2nd ed. Wiley, 1998.

63 National Institute of Health and Care Excellence. Antisocial behaviour and conduct disorders in children and young people: recognition, intervention and management. (Clinical guideline CG158.) 2013. www.nice.org.uk/guidance/cg158.

64 DuPaul GJ, Weyandt LL. School-based intervention for children with attention deficit hyperactivity disorder: effects on academic, social, and behavioural functioning. Int $J$ Dis Dev Educ 2006;53:161-76.

65 Antshel KM, Faraone SV, Gordon M. Cognitive behavioural treatment outcomes in adolescent ADHD. J Atten Disord 2012;18:483-95.

66 Moore D, Richardson M, Gwernan-Jones R, et al. Non-pharmacological interventions for ADHD in school settings: an overarching synthesis of systematic reviews. J Attention Dis 2015; published online 9 Mar.

67 Dunlap G, dePerczel M, Clarke S, et al. Choice making to promote adaptive behavior for students with emotional and behavioral challenges. J Applied Behav Anal 1994;27:505-18.

68 DuPaul GJ, Guevremont DC, Barkley RA. Behavioral treatment of attention-deficit hyperactivity disorder in the classroom. The use of the attention training system. Behav Modif 1992;16:204-25.

69 Sarver DE, Rapport M, Kofler MJ, et al. Hyperactivity in Attention-Deficit/Hyperactivity Disorder (ADHD): impairing deficit or compensatory behavior? J Abnorm Child Psychol 2015; published online $12 \mathrm{Apr}$

70 DuPaul GJ, Ervin RA, Hook CL, et al. Peer tutoring for children with attention deficit hyperactivity disorder: effects on classroom behaviour and academic performance. J App Behav Anal 1998;31:579-92.

71 Cunningham CE, Cunningham LJ, Martorelli V, et al. The effects of primary division, student-mediated conflict resolution programs on playground aggression. J Child Psychol Psychiatry 1998;39:653-62.

72 Pelsser LM, Frankena K, Toorman J, et al. Effects of a restricted elimination diet on the behaviour of children with attention-deficit hyperactivity disorder (INCA study): a randomised controlled trial. Lancet 2011;377:494-503.

73 King S, Griffin S, Hodges Z, et al. A systematic review and economic model of the effectiveness and cost-effectiveness of methylphenidate, dexamfetamine and atomoxetine 
for the treatment of attention deficit hyperactivity disorder in children and adolescents. Health Technol Assess 2006;10:iii-iv, xiii-146.

74 Banaschewski T, Coghill D, Santosh P, et al. Long-acting medications for the hyperkinetic disorders. A systematic review and European treatment guideline. Eur Child Adolesc Psychiatry 2006;15:476-95.

75 Pliszka S, AACAP Work Group on Quality Issues. Practice parameter for the assessment and treatment of children and adolescents with attention-deficit/hyperactivity disorder. $J$ Am Acad Child Adolesc Psychiatry 2007;46:894-921.

76 Michelson D, Allen AJ, Busner J, et al. Once-daily atomoxetine treatment for children and adolescents with attention deficit hyperactivity disorder: a randomized, placebo-controlled study. Am J Psychiatry 2002;159:1896-901.

77 Cortese S, Holtmann M, Banaschewski T, et al. Practitioner review: current best practice in the management of adverse events during treatment with ADHD medications in children and adolescents. J Child Psychol Psychiatry 2013;54:227-46.

78 Riddle MA, Yershova K, Lazzaretto D, et al. The Preschool Attention-Deficit/Hyperactivity Disorder Treatment Study (PATS) 6-year follow-up. J Am Acad Child Adolesc Psychiatry 2013;52:264-78.e2.

79 Collett BR, Ohan JL, Myers KM. Ten-year review of rating scales. V: scales assessing attention-deficit/hyperactivity disorder. J Am Acad Child Adolesc Psychiatry 2003;42:1015-37.

80 Cortese S, Faraone SV, Konofal E, et al. Sleep in children with attention-deficit/hyperactivity disorder: meta-analysis of subjective and objective studies. J Am Acad Child Adolesc Psychiatry 2009;48:894-908.
81 Hammerness PG, Perrin JM, Shelley-Abrahamson R, et al. Cardiovascular risk of stimulant treatment in pediatric attention-deficit/hyperactivity disorder: update and clinical recommendations. J Am Acad Child Adolesc Psychiatry 2011;50:978-90.

82 Poulton A, Briody J, McCorquodale T, et al. Weight loss on stimulant medication: how does it affect body composition and bone metabolism? A prospective longitudinal study. Int J Pediatr Endocrinol 2012;2012:30.

83 Bangs ME, Jin L, Zhang S, et al. Hepatic events associated with atomoxetine treatment for attention-deficit hyperactivity disorder. Drug Saf 2008;31:345-54.

84 Kratochvil CJ, Wilens TE, Greenhill LL, et al. Effects of long-term atomoxetine treatment for young children with attention-deficit/hyperactivity disorder. J Am Acad Child Adolesc Psychiatry 2006;45:919-27.

85 Chang Z, Lichtenstein P, Halldner L, et al. Stimulant ADHD medication and risk for substance abuse. J Child Psychol Psychiatry 2014;55:878-85.

86 Yemula C, Besag F, Coghill D. How is standard ADHD medication used in clinical practise and how is this supported by research? Cut Edge Psychiatry Pract 2013;2:35-45.

87 American Psychiatric Association. Diagnostic and statistical manual of mental disorders. 5th ed. APA, 2013

Cite this as: BMJ 2015;350:h2168

(c) BMJ Publishing Group Ltd 2015 


\section{Tables}

Table 1| Evidence for non-drug treatment for attention-deficit/hyperactivity disorder (ADHD)

\begin{tabular}{lcll} 
Treatment & Level of evidence & & \multicolumn{1}{l}{ Evidence } \\
Parent training & $1^{*}$ & Insufficient evidence $^{55}$ \\
\hline Cognitive training & 1 & More evidence needed $^{55}$ \\
\hline Cognitive behavioural therapy & $3 \dagger$ & Shown to be effective in adolescents receiving ADHD drug treatments $^{65}$ \\
\hline Social skills training & 1 & Insufficient evidence $^{56}$ \\
\hline Free fatty acid supplementation & 1 & Small but significant effects; clinical significance to be determined $^{55}$ \\
\hline Artificial food colour exclusion & 1 & Statistically significant, modest effects on ADHD symptoms $^{55}$ \\
\hline Restricted elimination diets & 1 & Insufficient evidence $^{55}$ \\
\hline
\end{tabular}

Levels of evidence from Oxford Centre for Evidence Based Medicine, 2011.

*Evidence from meta-analysis of randomised controlled trial.

†Evidence from non-randomised controlled cohort studies. 


\begin{tabular}{|c|c|c|c|c|c|c|c|}
\hline \multirow[b]{3}{*}{ Formulation } & \multirow{3}{*}{$\begin{array}{l}\text { Dexamphetamine } \\
\text { Tablet }\end{array}$} & \multirow{3}{*}{$\begin{array}{l}\text { Lisdexamfetamine } \\
\text { Elvanse (Shire, } \\
\text { UK) } \\
\text { Capsule, dissolvable }\end{array}$} & \multicolumn{4}{|c|}{ Methylphenidate } & \multirow{2}{*}{$\begin{array}{c}\text { Atomoxetine } \\
\text { (Strattera; Eli } \\
\text { Lilly, USA) }\end{array}$} \\
\hline & & & $\begin{array}{c}\text { Ritalin (Novartis, } \\
\text { Switzerland) or } \\
\text { methylphenidate } \\
\text { hydrochloride }\end{array}$ & $\begin{array}{l}\text { Medikinet XL } \\
\text { (Medice, } \\
\text { Germany) }\end{array}$ & $\begin{array}{l}\text { Equasym XL } \\
\text { (UCB Pharma, } \\
\text { Belgium) }\end{array}$ & $\begin{array}{c}\text { Concerta XL } \\
\text { Janssen-Cilag, } \\
\text { USA) }\end{array}$ & \\
\hline & & & Tablet $^{*}$ & Capsule† & Capsuleł & Tablet & Capsule \\
\hline $\begin{array}{l}\text { Immediate release: } \\
\text { extended release ratio } \\
\text { of methylphenidate }\end{array}$ & & & $\begin{array}{l}100 \% \text { immediate } \\
\text { release }\end{array}$ & $\begin{array}{l}50 \% \text { immediate } \\
\text { release, } 50 \% \\
\text { extended } \\
\text { release }\end{array}$ & $\begin{array}{l}30 \% \text { immediate } \\
\text { release, } 70 \% \\
\text { extended release }\end{array}$ & $\begin{array}{l}22 \% \text { immediate } \\
\text { release, } 78 \% \\
\text { extended release }\end{array}$ & \\
\hline $\begin{array}{l}\text { Approximate duration } \\
\text { of action (hours) }\end{array}$ & 4 & 13 & 4 & 8 & 8 & 12 & 24 \\
\hline Titration, starting dose & $\begin{array}{l}2.5 \mathrm{mg} \mathrm{2-3} \mathrm{times} \mathrm{a} \\
\text { day }\end{array}$ & $30 \mathrm{mg}$ & $\begin{array}{l}5 \mathrm{mg} 1-2 \text { times a } \\
\text { day }\end{array}$ & $5-10 \mathrm{mg}$ & $10 \mathrm{mg} / \mathrm{day}$ & $18 \mathrm{mg} / \mathrm{day}$ & $\begin{array}{l}<70 \mathrm{~kg} 0.5 \\
\mathrm{mg} / \mathrm{kg} / \mathrm{day} \text { for } 7 \\
\text { days }\end{array}$ \\
\hline $\begin{array}{l}\text { Titration, weekly } \\
\text { increase }\end{array}$ & $5 \mathrm{mg}$ a day & $20 \mathrm{mg}$ & $5-10 \mathrm{mg}$ & $10 \mathrm{mg}$ & $10 \mathrm{mg}$ & $9-18 \mathrm{mg}$ & $\begin{array}{l}\text { As much as } 1.2 \\
\mathrm{mg} / \mathrm{kg} / \mathrm{day}\end{array}$ \\
\hline $\begin{array}{l}\text { Equivalent daily dose } \\
\text { of } 30 \mathrm{mg} \\
\text { methylphenidate } \\
\text { hydrochloride }\end{array}$ & $15 \mathrm{mg}$ & & $30 \mathrm{mg}$ & $30 \mathrm{mg}$ & $30 \mathrm{mg}$ & $36 \mathrm{mg}$ & $\begin{array}{l}\text { NA, must follow } \\
\text { atomoxetine } \\
\text { protocol }\end{array}$ \\
\hline Frequency of dose/day & $2-3$ & 1 & $2-3$ & 1 & 1 & 1 & $\begin{array}{l}1 \text { or } 2 \text { divided } \\
\text { doses }\end{array}$ \\
\hline $\begin{array}{l}\text { Maximum licensed } \\
\text { dose/day }\end{array}$ & $20 \mathrm{mg}$ & $70 \mathrm{mg}$ & $60 \mathrm{mg}$ & $60 \mathrm{mg}$ & $60 \mathrm{mg}$ & $54 \mathrm{mg}$ & $\begin{array}{l}<70 \mathrm{~kg}, 1.8 \\
\mathrm{mg} / \mathrm{kg} / \text { day }\end{array}$ \\
\hline Controlled drug & Yes & Yes & Yes & Yes & Yes & Yes & No \\
\hline $\begin{array}{l}\text { Approximate cost for } \\
30 \text { tablets (UK } 2015 \\
\text { rates) }\end{array}$ & £26 (5 mg) & $£ 62(30 \mathrm{mg})$ & $£ 5.50(10 \mathrm{mg})$ & $£ 25(10 \mathrm{mg})$ & $£ 25$ (10 mg) & $£ 31(18 \mathrm{mg})$ & $£ 67(10 \mathrm{mg})$ \\
\hline Other & & $\begin{array}{l}\text { Licensed in Europe } \\
\text { for those with } \\
\text { inadequate response } \\
\text { to methylphenidate }\end{array}$ & & & & $\begin{array}{l}\text { Continuation } \\
\text { license for adult } \\
\text { use }\end{array}$ & \\
\hline
\end{tabular}

${ }^{*}$ Can be crushed, put in water, and drunk straight away.

†Can be sprinkled over tablespoon of apple sauce or yogurt (then swallowed without chewing).

$\ddagger$ Can be sprinkled over tablespoon of apple sauce (then swallowed without chewing). 
Table 3| How to manage different drugs for attention-deficit/hyperactivity disorder (ADHD)

\section{Drug} General comments

Short acting Allows greatest flexibility to adjust the drug to Younger children could start on a single morning methylphenidate the needs of children over the course of a day. dose of $5 \mathrm{mg}$, with gradual dose increases until a Administering the drug away from home can response is observed. The same process can then be difficult. Parents can top-up with additional be started for the afternoon dose, as different doses doses at their discretion; for example, when are often needed throughout the day children attend clubs after school

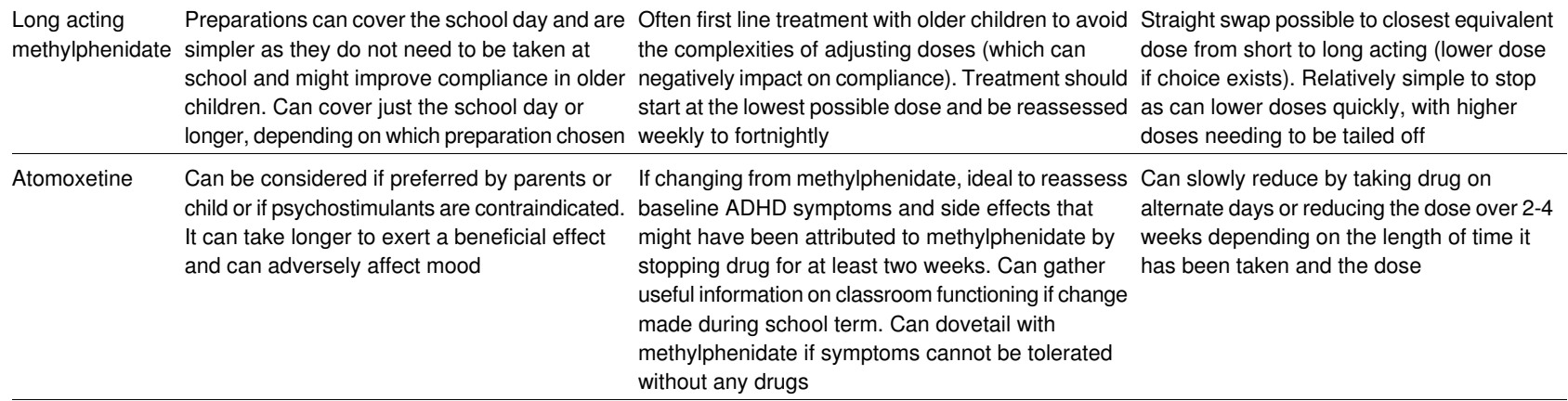

How to start

\section{How to change and stop}

Can do a straight swap to closest equivalent dose of long acting (usually to lower of two doses if a choice exists). Relatively simple to stop as can reduce doses quickly, with higher doses needing to be tailed off. 


\section{Figures}

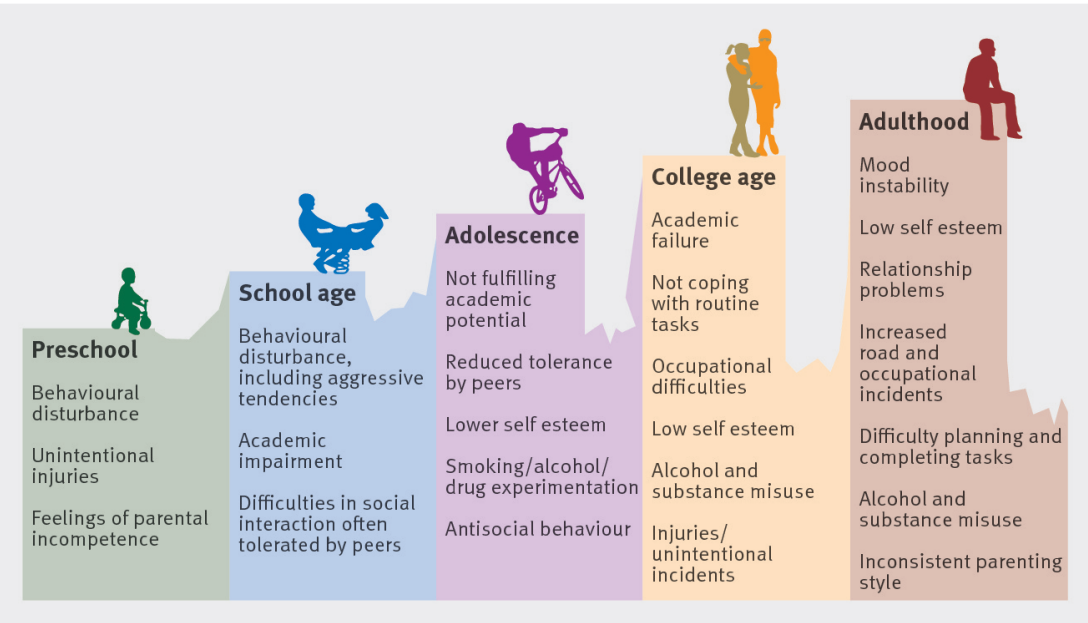

Fig 1 Possible developmental impacts of attention-deficit/hyperactivity disorder

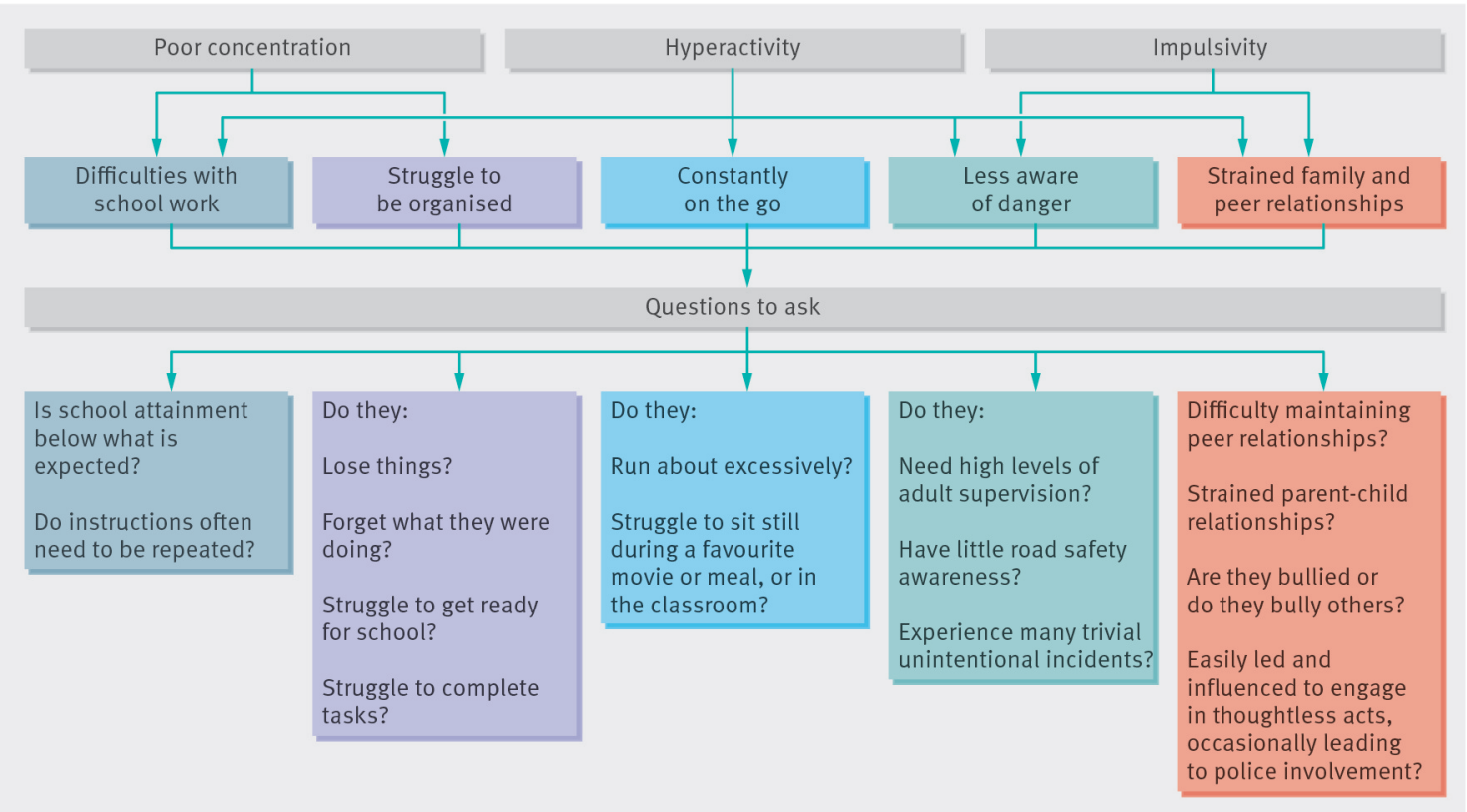

Fig 2 How to assess children for attention-deficit/hyperactivity disorder 